\title{
Fixed combination of topical brimonidine $0.2 \%$ and timolol $0.5 \%$ for glaucoma and uncontrolled intraocular pressure
}

\author{
Anne J Lee' \\ Peter McCluskey ${ }^{1,2}$ \\ 'Department of Ophthalmology, \\ Liverpool Hospital, Liverpool, NSW, \\ Australia; ${ }^{2}$ Faculty of Medicine, \\ University of New South Wales, \\ Randwick, NSW, Australia
}

\begin{abstract}
Lowering IOP is the most readily modifiable risk factor to delay the development and progression of glaucoma (POAG). The fixed combination of brimonidine tartrate $0.2 \%$ and timolol maleate $0.5 \%$ (FCBT) combines a highly selective $\alpha 2$-adrenergic agonist (brimonidine) with a non-selective $\beta$-blocker (timolol). FCBT reduces aqueous production and enhances uveoscleral outflow. Concomitant brimonidine and timolol have additive effects on reducing intraocular pressure (IOP). Multi-center randomized control trials have documented superiority of FCBT twice daily on IOP control compared with monotherapy with the individual components, and equal efficacy compared with concomitant therapy. IOP reduction with FCBT versus fixed combination dorzolamide $2 \%$ and timolol $0.5 \%$ (FCDT) was similar in a small study. Other studies ( $\mathrm{n}>293$ ) evaluating concomitant brimonidine and timolol have shown that it is not inferior to FCDT. However, concomitant brimonidine and timolol administered twice daily was significantly less efficacious in IOP reduction than fixed combination latanoprost $0.005 \%$ and timolol $0.5 \%$ (FCLT). There are no published studies comparing FCBT with FCLT. The side effect profile for FCBT reflects that of its individual components. FCBT was generally well tolerated, with less ocular side effects than brimondine alone, but more than timolol alone. Documented systemic effects were few, although this could be confounded by selection bias. FCBT is a safe and effective IOP lowering agent for POAG and ocular hypertension.
\end{abstract}

Keywords: brimonidine, timolol, combigan, glaucoma, combination, ocular hypertension

Several studies have highlighted the impact of glaucoma as a leading cause of blindness (Thylefors and Negrel 1994; Quigley 1996). The estimated number of people with vision loss from glaucoma range from 5.2 (Thylefors and Negrel 1994) to 6.7 million. This is approximately $10 \%$ of the total number of affected persons, ranking glaucoma as the second most common cause of world blindness (Quigley 1996). Primary openangle glaucoma (POAG) is a progressive optic neuropathy with corresponding optic disc cupping and glaucomatous visual field defects. The intraocular pressure (IOP) of the eye often exceeds its tolerance. Data from the Early Manifest Glaucoma trial (Heijl et al 2002) have shown that an additional $1 \mathrm{mmHg}$ of IOP lowering reduces the risk of glaucoma progression by $10 \%$. Participants of the Advanced Glaucoma Intervention Study (AGIS-7 2000) who achieved the target IOP of $<18 \mathrm{mmHg}$ at each visit had minimal deterioration of visual field over 96 months. Lowering IOP remains the most readily modifiable risk factor to delay development of glaucoma in subjects with ocular hypertension $(\mathrm{OH})$ and progression of POAG (Kass et al 2002).

Several classes of topical IOP-lowering agents are available. These include $\beta$-receptor antagonists (selective or nonselective), prostaglandin F2 $\alpha$-analogs and prostamides, $\alpha$-adrenergic agonists, carbonic anhydrase inhibitors, and cholinergic agents. Pharmacotherapy usually begins with a single topical agent (monotherapy), traditionally
Correspondence: Peter McCluskey Department of Ophthalmology, Liverpool Hospital, Locked Bag 7103, Liverpool BC NSW I87I, Australia

Email peter.mccluskey2@sswahs.nsw. gov.au 
a $\beta$-blocker. Since the introduction of prostaglandin analogues, many ophthalmologists prefer this agent as first-line treatment (Schwartz and Budenz 2004). Subsequent addition of a second agent (combination therapy) or more is often required to achieve target pressures. In the Ocular Hypertension Treatment Study, $40 \%$ of treated subjects required $>1$ medication to achieve the therapeutic goal of $20 \%$ IOP reduction from baseline (Kass et al 2002). More than $75 \%$ of subjects in the medical treatment arm of the Collaborative Initial Glaucoma Treatment Study (Lichter et al 2001) required $\geq 2$ medications after 2 years. One in two patients commenced on initial monotherapy will require additional ocular hypotensives within 2 years to control IOP (Kobelt-Nguyen et al 1998).

Modern adjunctive therapy combines a $\beta$-blocker with another class of drug such as a topical carbonic anhydrase inhibitor, prostaglandin analogue, or selective $\alpha$-agonist (Fechtner and Realini 2004). For example, timolol 0.5\% is combined as an invariant with dorzolamide $2 \%\left(\mathrm{Cosopt}^{\circledR}\right.$, Merck and Co, Inc., Whitehouse Station, NJ, USA), latanoprost $0.005 \%$ (Xalacom ${ }^{\circledR}$, Pharmacia Inc., Peapack, NJ, USA), brimonidine $0.2 \%$ (Combigan ${ }^{\mathrm{TM}}$, Allergan Inc., Irvine, CA, USA), travoprost 0.004\% (Duotrav ${ }^{\circledR}$, Alcon Inc., Fort Worth, TX, USA), or bimatoprost $0.03 \%$ (Ganfort $^{\circledR}$, Allergan Inc., Irvine, CA, USA) (Frampton 2006).

Fixed combinations of glaucoma medications offer numerous advantages for patients requiring multi-drug regimens. Most important is enhanced patient compliance. Fixed combinations allow reduction of the number of drops instilled per day and bottles of medication purchased thus overall cost to the individual and the time commitment for drop instillation. There is less confusion with drop regime, particularly for the older patient. There is no washout effect which arises from rapid instillation of multiple medications (Chrai et al 1974). Exposure to preservatives is minimized, thus reducing subclinical ocular surface inflammation and glaucoma filtering surgery failure rates (Broadway et al 1994). However, in some patients, concomitant therapy may be required over fixed dosing for more individually tailored IOP control.

This review focuses on the efficacy and safety profile of fixed combination brimonidine tartrate $0.2 \%$ and timolol maleate $0.5 \%$ ophthalmic solution for the treatment of glaucoma and ocular hypertension $(\mathrm{OH})$.

\section{Pharmacology - mechanism of action}

Fixed combination brimonidine/timolol (FCBT) consists of two active substances: brimonidine tartrate
$2.0 \mathrm{mg} / \mathrm{mL}$ (1.3 mg brimonidine free base) and timolol maleate $6.8 \mathrm{mg} / \mathrm{mL}$ (5.0 mg timolol) (MIMS 2007).

\section{Brimonidine tartrate}

Brimondine tartrate is a potent and highly selective $\alpha_{2}$-adrenergic agonist, compared with apraclonidine or clonidine (Burke and Schwartz 1996; Cantor 2000) thus reducing mydriasis, lid retraction, and vasoconstriction. It is suggested that brimonidine lowers IOP by reducing aqueous humor production (Larsson 2001) and enhancing uveoscleral outflow (Serle et al 1991; Toris et al 1995). In addition, brimonidine has exhibited neuroprotective activity in experimental neuronal injury models, including light-induced photoreceptor damage (Wen et al 1996), optic nerve crush injury (Yoles et al 1999), acute retinal ischemia (Villegas-Perez et al 2000), and ocular hypertensive retinas (WoldeMussie et al 2001). In vivo evidence for neuroprotection is minimal. Reduced retinal nerve fiber layer damage after brimonidine $0.2 \%$ compared with timolol $0.5 \%$ has been found in $\mathrm{OH}$ patients over 1 year (Tsai and Chang 2005). Putative mechanisms of neuroprotection include increase in neurotrophic factors, thus enhancing retinal ganglion cell survival or activation of presynaptic $\alpha 2$-receptors with inhibition of neurotransmitter release in particular glutamate. Brimonidine has a rapid onset of action, with peak ocular hypotensive effect at 2 hours post-dosing. The duration of effect is 12 hours or greater.

\section{Timolol maleate}

Timolol maleate is a nonselective $\beta$-adrenergic antagonist that does not have significant intrinsic sympathomimetic, direct myocardial depressant or local anesthetic (membrane stabilizing) activity. The precise mechanism of action of timolol in IOP lowering is not fully elucidated, but the predominant action relates to suppression of aqueous secretion (Kiland et al 2004). Onset of action is 20 minutes postdosing, with peak effect at 1-2 hours. Significant lowering of IOP has been maintained as long as 24 hours.

The IOP lowering efficacy of brimonidine has been demonstrated in animal models (Burke and Potter 1996), and in human subjects with normal IOP (David et al 1995), ocular hypertension, or glaucoma (Derick et al 1997). Several large clinical trials have also established the efficacy of brimonidine compared with timolol. The Brimonidine Study Group (Schuman 1996; Katz et al 1999) pooled results from Brimonidine Study Groups 1 (Schuman et al 1997) and 2 (Le Blanc et al 1998), 2 large multi-center, randomized, double masked, trials of 12 months' duration. Among 837 patients with glaucoma (61\%) or $\mathrm{OH}(39 \%)$, 
both brimonidine $0.2 \%$ twice daily and timolol $0.5 \%$ twice daily significantly reduced mean IOP $(p<0.001)$ from baseline levels at every subsequent follow-up visit, both at peak ( 2 hours post dose) and trough times (12 hours post dose). Mean changes from baseline IOP ranged from $5.0-6.2 \mathrm{mmHg}$ in the brimonidine group $(\mathrm{p}<0.001)$ and $5.8-6.5 \mathrm{mmHg}$ in the timolol group ( $\mathrm{p}<0.001)$. Overall, brimonidine showed efficacy comparable to than of timolol, and is a safe, effective long-term IOP-lowering agent (Schuman 1996; Melamed et al 2000).

Javitt et al evaluated the efficacy of brimonidine $0.2 \%$ twice daily and timolol $0.5 \%$ twice daily in 211 POAG and $\mathrm{OH}$ subjects (Javitt et al 2000). Subjects were naïve to treatment, thus eliminating possible $\beta$-blocker responsiveness and tolerability found in other studies where subjects had responded to $\beta$-blockers (Schuman 1996). The overall mean decrease in IOP was $6.5 \mathrm{mmHg}$ with brimonidine and $6.2 \mathrm{mmHg}$ with timolol over 4 months. These rates were comparable with other studies where the inherent selection bias described above could be an issue (Schuman 1996). Approximately 30\% of each group did not achieve clinical success.

Van der Valk et al performed a meta-analysis of randomized clinical trials of all commonly used glaucoma agents for POAG or OH subjects (van der Valk et al 2005). In this study, only single agents were evaluated. For brimonidine $0.2 \%$ twice daily, the pooled 1-month relative mean IOPlowering effect from baseline was $-25 \%$ at peak and $-18 \%$ at trough levels. For timolol $0.5 \%$ twice daily, the values for relative mean IOP-lowering from baseline were $-27 \%$ (peak) and $-26 \%$ (trough). Greatest IOP lowering effect at peak was found with bimatoprost at $-33 \%$, and at trough was travoprost at $-29 \%$. This meta-analysis concluded that bimatoprost, travoprost, latanoprost, and timolol are the most effective IOP-reducing agents in POAG and $\mathrm{OH}$ patients (van der Valk et al 2005).

\section{Concomitant brimonidine and timolol therapy}

Studies of concomitant brimonidine $0.2 \%$ and timolol $0.5 \%$ have shown additive IOP-lowering effects. Larsson observed that the reduction in aqueous humor production (58.9\%) and IOP (34.7\%) was greater after combined brimonidine and timolol, than timolol (reduced aqueous humor production $49.9 \%$ and IOP $22.9 \%$ ) or brimonidine (reduced aqueous humor production $33.1 \%$ and IOP 20.3\%) monotherapy (Larsson 2001). Yuksel et al also demonstrated additive IOPlowering effects of adjunctive brimonidine over 2 days (Yuksel et al 1999). POAG or pseudoexfoliative glaucoma subjects
( $\mathrm{n}=15)$ on timolol twice daily and IOP of $\geq 22 \mathrm{mmHg}$ in at least one eye, were randomized to adjunctive brimonidine $0.2 \%$ daily or placebo. A statistically significant decrease in IOP at each time interval $(1,2,4,6$, and 8 hours post dose at day 1 and 2) was found compared with the placebo/timolol group ( $\mathrm{p}>0.05$ ). Maximum IOP decrease of $7.26 \mathrm{mmHg}$ was documented at 4 hours with concomitant therapy. Overall additional maximum IOP-lowering effect of brimondine $0.2 \%$ daily administered adjunctively with timolol twice daily was 19.23\% (Yuksel et al 1999).

Another similar study (Arici et al 2002) evaluated the effect of adjunctive brimonidine in timolol-treated subjects over a longer time period of 3 weeks. IOP reduction of $5.1 \mathrm{mmHg}(21.2 \%), 5.9 \mathrm{mmHg}(24.5 \%)$, and $5.7 \mathrm{mmHg}$ $(23.6 \%)$ at weeks 1,2 , and 3 respectively was found. Centofanti et al evaluated unfixed combination of timolol and brimonidine on timolol uncontrolled glaucomatous patients (Centofanti et al 1999). IOP further decreased by $16.1 \%$ and $24.7 \%$ after 1 and 3 months respectively with adjunctive brimonidine $0.2 \%$ twice daily. In a larger study of 552 subjects with POAG or $\mathrm{OH}$ and IOP $\geq 20 \mathrm{mmHg}$ in each eye, adjunctive brimonidine also significantly lowered IOP when added to any pre-existing drop regimen (Lee and Gornbein 2001).

\section{Fixed combination brimonidine/timolol trials}

There are a small number of studies evaluating fixed combination brimonidine $0.2 \% /$ timolol $0.5 \%$ (FCBT). The Combigan Study Groups I and II pooled data from two identically designed multicenter, randomized, double masked, parallelgroup trials. Both studies evaluated FCBT twice daily versus monotherapy with the individual components; brimonidine $0.2 \% 3$ times daily or timolol $0.5 \%$ twice daily. Data at 3 (Craven et al 2005) and 12 (Sherwood et al 2006) months were published. Twelve-month data are discussed here.

Eligible subjects were $\geq 18$ years and required bilateral treatment for POAG or $\mathrm{OH}$. Washout period was up to 4 weeks depending on type of IOP-lowering medication at baseline. Baseline IOP after wash-out was $22-34 \mathrm{mmHg}$ in each eye, with no greater than $5 \mathrm{mmHg}$ difference between eyes. Best corrected visual acuity was 20/100 or better in both eyes. Subjects with active ocular disease, functionally significant or progressive visual field loss in the previous year, abnormally low or high blood pressure or pulse rate, or contraindications or sensitivity to any component of the study treatment were excluded.

At the baseline visit, IOP was measured at 0800, 1000, 1500 , and 1700 hours. Patients were then randomly assigned 
to 1 of 3 treatment groups using a 1:1:1 allocation of FCBT: timolol:brimondine. Patients self-instilled 1 drop of the appropriate study medication into both eyes 3 times daily, with a vehicle solution in the afternoon if randomized to the brimonidine/timolol or timolol group. Follow-up visits were scheduled at weeks 2 and 6 and at months 3, 6, 9, and 12 . IOP was measured at $0800,1000,1500$, and 1700 at these visits except the 9-month visit when IOP was measured at 0800 and 1000 .

Of 1159 patients enrolled in the study, 385 subjects received FCBT, 382 subjects brimonidine, and 392 subjects timolol. A total of 833 patients $(71.9 \%)$ completed 12 months' treatment. Discontinuation rates were greatest in the brimonidine-treated group (169/1159) compared with the FCBT (99/1159) or timolol (58/1159) treated groups. Demographic characteristics were similar between groups, except more females in the brimonidine-treated group. Mean age was 62.6 years (29-89 years), 75.8\% were white.

The mean IOP at the 0800, 1000, and 1500 measurements at baseline were similar between groups. At 1700, mean baseline IOP was lower in the FCBT group than the timolol group $(p=0.01)$ or the brimonidine group $(p=0.06)$. The mean decrease from baseline IOP at the 22 measured time points ranged from 4.4-7.6 $\mathrm{mmHg}$ with FCBT, 2.7-5.5 $\mathrm{mmHg}$ with brimonidine, and 3.9-6.2 $\mathrm{mmHg}$ with timolol. Analyses showed a significantly greater decrease in IOP in the FCBT group compared with timolol group at all measurements, and brimonidine group at all measurements except the 1700 measurements, which was 2 hours after the mid-day brimonidine dose.

Daytime mean IOP was also lower in the FCBT group compared with the timolol group at all measurements $(\mathrm{p} \leq 0.002)$ and the brimonidine group at 0800,1000 , and 1500 $(\mathrm{p}<0.001)$, and 1700 at week $6(\mathrm{p}=0.04)$. Mean daytime IOP of $<18 \mathrm{mmHg}$ was maintained by $39.5 \%$ of the FCBT group compared with $14.9 \%$ and $21.7 \%$ of those treated with brimonidine or timolol respectively. A mean daytime decrease from baseline IOP of greater than $20 \%$ at every follow-up visit was significantly greater in the FCBT group (42.1\% of patients), than the brimonidine (13.1\%) or timolol (27.3\%) group.

The distribution of patients across the target pressure ranges of $<14.0,14.0-17.5$, and $>17.5 \mathrm{mmHg}$ favored the FCBT group over brimonidine or timolol monotherapy. There was a significantly greater shift towards the lowest pressure range $(<14.0 \mathrm{mmHg})$ in the FCBT group than in either of the monotherapy groups ( $p<0.001$ ).

In summary, this study (Sherwood et al 2006) demonstrated that the mean decreases from baseline IOP, mean daytime
IOP, and mean daytime IOP $<18 \mathrm{mmHg}$ were significantly greater in the FCBT group compared with monotherapy of its constituent parts. Two-fold increased number of FCBT subjects achieved $>20 \%$ reduction in IOP compared with timolol monotherapy, and 3-fold compared with brimonidine monotherapy.

\section{Versus concomitant therapy with the individual components}

The Brimonidine/Timolol Fixed Combination Study Group (Goni et al 2005) evaluated the efficacy and safety of FCBT twice daily compared with unfixed concomitant use of brimonidine and timolol each given twice daily. Methodology of this randomized multi-center double-masked parallel group study is similar to that of the Combigan Study Group I and II described earlier (Craven et al 2005; Sherwood et al 2006). There are a few differences; this study (Goni et al 2005) also included patients with chronic angle-closure, pseudo-exfoliative or pigmentary glaucoma. IOP elevation was of a similar range $(22-34 \mathrm{mmHg})$ but only required in at least 1 eye and after $\geq 3$ weeks of runin monotherapy of the investigator's choice, continuation of current monotherapy, or cessation of all but one agent if multiple agents used. After baseline IOP measurement at hour 0 , subjects were randomized into FCBT or concomitant groups in 1:1 ratio. Run-in monotherapy was discontinued. IOP measurements were taken at hour 0 and 2 at baseline, weeks 2, 6, and 12 .

A total of 355 patients (96\%) completed the study. Most were white $(97.3 \%)$ and the majority female (62.8\%). Types of run-in monotherapy ( $\beta$-blockers [65.0\%], brimonidine [15.6\%], carbonic anhydrase inhibitor [10.5\%], prostaglandin analog [7.8\%], or other [1.1\%] topical medications) were statistically similar between groups.

Both FCBT and concomitant therapy showed statistically significant mean IOP reductions from monotherapy treated baseline at each follow-up time point $(\mathrm{p}<0.001)$ (Goni et al 2005). At hour 0 (trough) for each time point (weeks $2,6,12)$, the mean IOP reduction from baseline ranged from 4.4 to $4.9 \mathrm{mmHg}$ in each treatment group. At hour 2 (peak) mean IOP reduction ranged from 4.9 to $5.3 \mathrm{mmHg}$ in the fixed combination group and from 4.7 to $5.3 \mathrm{mmHg}$ in the concomitant group. This was not significantly different between groups.

The mean change from baseline compared with hour 0 , week 12 IOP (the primary efficacy endpoint) was $-4.9 \mathrm{mmHg}$ for both groups, and the upper limit of the $95 \%$ confidence interval (CI) for the difference between groups was 0.79 , 
thus demonstrating noninferiority of combination treatment compared with concomitant therapy. Mean IOP at follow-up measurements ranged from 17.3 to $20.6 \mathrm{mmHg}$ in the FCBT group and from 17.1 to $20.5 \mathrm{mmHg}$ in the concomitant group, again not significantly different. Among patients run-in on timolol monotherapy, no difference was found between treatment groups. Patients run-in on other medications also showed similar mean changes from baseline IOP between treatment groups.

The percentages of subjects in each treatment group who achieved target pressures of $\leq 18 \mathrm{mmHg}$ were comparable; $33.0 \%$ and $37.2 \%$ of subjects in FCBT and concomitant group respectively at hour 0 , week 12 , and $70.2 \%$ and $70.5 \%$ at hour 2 , week 12 . An average IOP $\leq 17.5 \mathrm{mmHg}$ over all follow-up measurements was comparable between treatment groups $(29.3 \%$ FCBT vs $29.5 \%$ concomitant group).

This clinical trial has thus demonstrated that FCBT is noninferior to concomitant therapy. The primary efficacy endpoint compared baseline with IOP at week 12, where washout of previous monotherapy would not have confounded results. Measurements for mean change from baseline IOP, mean IOP at follow-up, and percentage of subjects achieving target pressures $\leq 18 \mathrm{mmHg}$, were also statistically similar between the two groups.

A more recent randomized controlled trial (Konstas et al 2007) has evaluated the 24-hour IOP control of FCBT versus the combination of its individual components, each dosed twice daily, in patients with POAG or OH. After a 6-week wash-out period, 28 patients were randomized to FCBT or to the unfixed combination for 3 months and then crossed over to the opposite treatment for another 3 months. Twenty-four hour IOP measurements (0600, 1000, 1400, 1800, 2200, and 0200 hours) were performed after the wash-out period and each treatment period. The mean 24-hour IOP was $24.6 \mathrm{mmHg}$ for baseline, $19.2 \mathrm{mmHg}$ for the FCBT group, and $19.2 \mathrm{mmHg}$ for the concomitant group. Both FCBT and the unfixed components showed a significant IOP reduction from untreated baseline $(\mathrm{p}<0.0001)$. The two treatment groups were statistically equal when compared directly, for each individual time point and for the 24-hour IOP curve $(\mathrm{p}>0.05)$.

\section{Versus dorzolamide/timolol}

Dorzolamide hydrochloride is a topical carbonic anhydrase inhibitor which was initially developed for use as monotherapy. Carbonic anhydrase found in the ciliary processes of the eye is inhibited, thus decreasing production of bicarbonate and subsequent sodium fluid transport. IOP is lowered by reducing aqueous secretion. A fixed combination of timolol maleate $0.5 \%$ and dorzolamide hydrochloride 2\% (FCDT) was introduced in 1998. Clinical studies have demonstrated comparable efficacy of the FCDT product with concomitant administration (Strohmaier et al 1998), and greater than either of its component parts (Boyle et al 1998; Clineschmidt et al 1998).

Centofanti et al (2000) explored the IOP-lowering effect of adding brimonidine $0.2 \%$ or dorzolamide $2 \%$ on 28 patients (right eye of each subject) with advanced POAG and a visual field mean defect of -10 to $-16 \mathrm{~dB}$. Patients were on timolol $0.5 \%$ twice daily treatment. Adjunct medication was administered in a masked fashion 2 hours after timolol dose, and IOP measured at 2-hour intervals. Adjunctive treatment was crossed over 3 weeks later, and IOP measured as for visit 1. Mean pretreatment IOP for all the group was $19.36 \mathrm{mmHg}$. As an adjunct to topical $\beta$-blockers, 1 drop of brimonidine $0.2 \%$ was more effective $(\mathrm{p}<0.05)$ than 1 drop of dorzolamide $2 \%$ in lowering IOP at 4 hours (mean IOP decrease $28.4 \mathrm{mmHg}$ vs $17.6 \mathrm{mmHg}$; $\mathrm{p}=0.04$ ) and at 8 hours (mean IOP decrease $35.5 \%$ vs $21.6 \%$; $=0.04$ ). Safety profiles were not published.

The Alphagan/Trusopt Study Group (Simmons et al 2001) randomly assigned 106 POAG or OH patients using a nonselective or selective topical $\beta$-blocker to receive brimonidine $0.2 \%$ twice daily or dorzolamide $2 \% 3$ times daily as adjunctive therapy for 3 months. IOP was inadequately controlled on $\beta$-blocker monotherapy (IOP 18-34 mmHg in each eye). Cross over of study medication occurred if the target $15 \%$ reduction in IOP at peak drug effect was not achieved after 1 month. Most patients were on timolol (61.3\%), and most had POAG (61.3\%).

Mean baseline IOP (with $\beta$-blocker monotherapy) was comparable between treatment groups $(21.56 \mathrm{mmHg}$ in the brimonidine vs $20.89 \mathrm{mmHg}$ in the dorzolamide group, $\mathrm{p}=0.284$ ) (Simmons et al 2001). At 1 month, the mean IOP reduction at peak effect was significantly greater in the brimonidine group $(5.95 \mathrm{mmHg}, 27.6 \%)$ than in the dorzolamide group $(4.11 \mathrm{mmHg}, 19.7 \% ; \mathrm{p}=0.007)$. This was not statistically different at 3 months $(6.39 \mathrm{mmHg}$ with brimonidine and $4.06 \mathrm{mmHg}$ with dorzolamide, $\mathrm{p}=0.059$ ). However, among patients who had achieved the target IOP reduction at month 1 , a greater percentage of brimonidinetreated patients $(77.8 \%, 28 / 36)$ met the target IOP at month 3 than did dorzolamide-treated subjects (44.4\%, 12/27, $\mathrm{p}=0.007$ ). Additionally, 2-fold increased rates of IOP reduction of $\geq 25 \%$ at month 3 were seen in the brimonidine-treated 
group (61.1\%) compared with the dorzolamide-treated group $(33.3 \%, p=0.029)$. These two trials (Centofanti et al 2000; Simmons et al 2001) suggest that brimonidine is more powerful and better sustained in reducing IOP than dorzolamide when added to $\beta$-blocker treatment.

Two randomized, observer-masked, multi-center trials have compared the efficacy of FCDT with the concomitant administration of brimonidine $0.2 \%$ twice daily and timolol $0.5 \%$ twice daily (Sall et al 2003; Solish et al 2004). Sall et al enrolled 293 participants with POAG or OH with IOP $\geq 22 \mathrm{mmHg}$ at hour 2 in at least 1 eye after an open-label 3 -week timolol ( $0.5 \%$ twice daily) run-in period (Sall et al 2003). Subjects were randomized to receive FCDT twice daily or the concomitant use of brimonidine twice daily and timolol twice daily for 6 months. At month 3, hour 2, the mean change in IOP in the FCDT group was $-5.04 \mathrm{mmHg}$ versus $-5.41 \mathrm{mmHg}$ in the brimonidine and timolol group, with a treatment difference of $0.36 \mathrm{mmHg}(95 \% \mathrm{CI}$ of -0.42 to $1.14 \mathrm{mmHg}$ ). At all other observed time points treatments were considered comparable as the $95 \%$ CI of the treatment difference was within $\pm 1.5 \mathrm{mmHg}$. This study was observermasked to maintain drop stability.

Solish et al aimed to replicate the results of the aforementioned study (Sall et al 2003) using a larger cohort of 492 patients with POAG or $\mathrm{OH}$, and in addition pseudoexfoliative or pigmentary glaucoma (Solish et al 2004). Run-in with timolol $0.5 \%$ was conducted in a similar manner to the initial study (Sall et al 2003). Study duration was 3 months. At month 3, hour 2, the mean change from baseline IOP among the FCDT group was $-4.30 \mathrm{mmHg}$ versus $-5.27 \mathrm{mmHg}$ in the brimonidine and timolol group, with a treatment difference of $0.97 \mathrm{mmHg}(95 \% \mathrm{CI}$ $0.40,1.53)$. The point estimate $(0.97 \mathrm{mmHg})$ was within the $\pm 1.5 \mathrm{mmHg}$ comparability boundary, although the $95 \%$ CI of $0.40,1.53$ exceeded this boundary. At month 3, hour 0 , the mean change in IOP from baseline was $-3.31 \mathrm{mmHg}$ compared with $3.52 \mathrm{mmHg}$ for the brimonidine + timolol group. The treatment difference was $0.21 \mathrm{mmHg}$ with $95 \%$ CI of -0.39 to $0.82 \mathrm{mmHg}$ (Solish et al 2004). As IOPlowering effects on all other time points were similar, the authors concluded that the difference found at month 3 , hour 2, was not likely to be meaningful clinically and FCDT was comparable to concomitant brimonidine and timolol.

A more recent but smaller prospective, multi-center, randomized, cross-over trial has compared FCBT with FCDT given twice daily in subjects $\geq 18$ years with POAG $(n=16)$ or OH $(\mathrm{n}=14)$ in at least 1 eye (Arcieri et al 2007). Other inclusion criteria were baseline IOP of 22-34 $\mathrm{mmHg}$ (not on medications) and best corrected visual acuity of 20/200 or better. Of eyes not included in the study, IOP must have been controllable on no medication or on the study medication. After wash-out of previous treatment, subjects were randomized to FCBT or FCDT for the first 4-week treatment period. Subjects then were again washed for 4 weeks and started on the opposite medication for the second 4 -week period. IOP was measured at 0800,1200 , and 1600 hours at each baseline and at the end of each treatment period.

The baseline mean diurnal IOP for all 30 subjects (30 eyes) was $22.9 \mathrm{mmHg}$. No difference was found in the mean diurnal IOP after 4 weeks of therapy $(15.0 \mathrm{mmHg}$ for FCBT and $15.4 \mathrm{mmHg}$ for FCDT, $\mathrm{p}=0.510)$. No difference was found in the mean diurnal IOP reduction $(7.8 \mathrm{mmHg}$ for FCBT and $7.4 \mathrm{mmHg}$ for FCDT, $\mathrm{p}=0.430$ ). Both fixed combinations significantly reduced IOP compared with baseline $(\mathrm{p}<0.00001)$. This study suggests that FCBT and FCDT have similar efficacy in POAG or OH. Patients were not masked to their study therapy, but investigators were masked. Investigators attempted to limit this potential bias through a randomizing crossover design.

\section{Versus latanoprost}

Latanoprost is an F2 $\alpha$-prostaglandin analog and is highly selective for the FP receptor (Stjernschantz and Resul 1992). It reduces IOP levels by increasing uveoscleral outflow with little or no effect on aqueous humour production (Toris et al 1993; Ziai et al 1993). Studies have shown that latanoprost daily is more effective than timolol twice daily in reducing IOP (Alm and Stjernschantz 1995; Camras 1996; Mishima et al 1996). Latanoprost has also been shown to be more effective than brimonidine $0.2 \%$ twice daily (Stewart et al 2000a; Stewart et al 2001). In a retrospective review of clinical files, Stewart et al compared the efficacy of latanoprost $0.005 \%$, brimonidine $0.2 \%$, or dorzolamide $2 \%$ when added to a topical $\beta$-blocker for at least 3 months in patients with POAG or $\mathrm{OH}$ (Stewart et al 2000b). Participants on latanoprost $(\mathrm{n}=50)$ showed an IOP of $16.7 \mathrm{mmHg}$ and reduction from baseline of $-6.3 \mathrm{mmHg}$. Those on brimonidine $(\mathrm{n}=24)$ showed an IOP of $17.4 \mathrm{mmHg}$ and reduction from baseline of $-4.2 \mathrm{mmHg}, \mathrm{p}<0.001$ and on dorzolamide $(\mathrm{n}=67)$ an IOP of $20.1 \mathrm{mmHg}$ and reduction of $-3.1 \mathrm{mmHg}$, $\mathrm{p}<0.001$. A significant difference was observed between groups in success rates (defined as reduction in IOP $\geq$ $3 \mathrm{mmHg}$ ); latanoprost $70 \%$, brimonidine $58 \%$, dorzolamide $40 \%, p=0.008$ (Stewart et al 2000b).

To date, there are no published studies of FCBT versus fixed combination latanoprost/timolol (FCLT). However, 
2 studies have compared FCLT daily versus concomitant brimonidine and timolol twice daily (Stewart et al 2003; Garcia-Sanchez et al 2004). Stewart et al randomized 32 subjects with POAG or OH to FCLT or concomitant brimondine and timolol twice daily (Stewart et al 2003). IOP in the study eye after 1 month of timolol administered twice daily ranged from 21 to $34 \mathrm{mmHg}$. Treatment was crossed-over after 6 weeks. IOP was measured every 2 hours between 0800 and 2000 hours at baseline and at the end of each treatment period. Compared with timolol alone $(20.9 \mathrm{mmHg})$ mean diurnal IOP decreased to $17.9 \mathrm{mmHg}$ when patients were treated with fixed combination timolol/latanoprost, and decreased to $19.0 \mathrm{mmHg}$ when patients were treated with brimonidine and timolol $(\mathrm{p}=0.02)$. When treatment groups were compared directly, a greater statistical reduction in IOP was found among those using FCLT. The greatest difference in IOP between treatment groups was at 12 hours post dosing. This study suggests that FCLT given in the evening reduces the mean daytime diurnal IOP more than brimonidine and timolol given concomitantly twice daily.

A multi-center European study evaluated IOP in 325 patients with POAG or OH on FCLT given in the morning or concomitant brimonidine/timolol given twice daily (GarciaSanchez et al 2004). For inclusion, subjects had IOP $\geq 21$ $\mathrm{mmHg}$ on monotherapy, or $>16 \mathrm{mmHg}$ on dual therapy. At baseline, mean diurnal IOP was $26.4 \mathrm{mmHg}$ for the FCLT group and $26.5 \mathrm{mmHg}$ for the concomitant brimonidine/timolol group. After 6 months, mean diurnal IOP was significantly lower in the FCLT group (16.9 $\mathrm{mmHg}$ ) compared with the brimonidine/timolol group (18.2 $\mathrm{mmHg}), \mathrm{p}<0.001$. FCLT administered once daily is both more effective and better tolerated than dosing twice daily with unfixed brimonidine/ timolol concomitant treatment.

Indeed, in a large post-hoc analysis, addition of brimonidine to a nonselective $\beta$-blocker reduced IOP by an additional $15.5 \%$ (3.61 mmHg, $\mathrm{p}<0.001)$. When brimonidine was added to latanoprost, the mean additional IOP reduction was 2-fold at 32.2\% (5.89 mmHg, p < 0.001) (Lee and Gornbein 2001). Thus, studies evaluating concomitant latanoprost and brimonidine versus FCBT may also be helpful in determining IOP lowering efficacy. The combination of a prostaglandin analog with an $\alpha$-agonist will also eliminate the cardiopulmonary adverse effects of timolol.

\section{Pharmacokinetics}

Both brimonidine $0.2 \%$ and timolol $0.5 \%$ are rapidly absorbed into ocular tissues after topical application. After FCBT, the terminal half-life in aqueous (rabbits) for brimonidine was 1.23 hours, and for timolol 1.12 hours. Peak plasma concentration $\left(\mathrm{C}_{\max }\right)$ and area under the plasma concentration time curve (0-12 hours) (AUC) were not significantly different between FCBT and the respective monotherapies. $\mathrm{C}_{\max }$ values were $32.7 \mathrm{pg} / \mathrm{mL}$ and $0.41 \mathrm{ng} / \mathrm{mL}$, AUC values $128 \mathrm{pg} . \mathrm{h} / \mathrm{mL}$ and $2.92 \mathrm{ng} . \mathrm{h} / \mathrm{mL}$, and time to $\mathrm{C}_{\max }\left(\mathrm{T}_{\max }\right)$ values 1.28 hours and 2.42 hours for brimonidine and timolol, respectively, after FCBT twice daily administration for 7 days to 16 healthy volunteers. Plasma brimonidine concentration after 2 weeks and 12 months of FCBT twice daily was $61.0 \mathrm{pg} / \mathrm{mL}$ and $56.2 \mathrm{pg} / \mathrm{mL}$ in one study and $50.6 \mathrm{pg} / \mathrm{ml}$ and $51.5 \mathrm{pg} / \mathrm{ml}$ for the other study, respectively. Plasma timolol concentration was $0.74 \mathrm{ng} / \mathrm{mL}$ and $0.55 \mathrm{ng} / \mathrm{mL}$ in one study, and $0.50 \mathrm{ng} / \mathrm{mL}$ and $0.54 \mathrm{ng} / \mathrm{mL}$ for the other study, respectively. These concentrations were lower than those for respective monotherapies in both studies. Also, concentrations did not increase over time.

When systemically absorbed, brimonidine (29\%) and timolol $(<10 \%)$ are not extensively bound to human plasma protein. Brimonidine and timolol are partially metabolized by the liver (mediated by aldehyde oxidase and cytochrome P450 for brimonidine), and primarily excreted by the kidneys. After FCBT for 7 days, plasma elimination half-life value was 2.43 hours for brimondine and 7.32 hours for timolol.

\section{Safety}

Tolerability and treatment-related adverse events profile of FCBT were evaluated simultaneously in most of the larger studies mentioned. Use of FCBT was associated with fewer side effects than brimonidine alone $(\mathrm{p}=0.006)$, but more than timolol alone $(\mathrm{p}<0.001)$ (Sherwood et al 2006). In this study, $28.1 \%$ of subjects discontinued treatment; $16.6 \%$ had adverse events, $4.6 \%$ due to poor efficacy, and $7.0 \%$ other reasons. FCBT subjects had a lower incidence of $1+$ treatment-related adverse events $(53.0 \%$ vs $62.8 \%)$, discontinuations due to adverse events (14.3\% vs 30.6\%), and at least a 1-grade increase in severity in biomicroscopic findings ( $54.8 \%$ vs $62.8 \%$ ) compared with the brimonidinetreated group. Compared with the timolol-treated group, higher rates of $1+$ treatment-related adverse events $(53.0 \%$ vs $40.8 \%)$ and discontinuations due to adverse events (14.3\% vs $5.1 \%$ ) were found.

Of individual adverse events, the brimonidine group had higher rates of conjunctival hyperemia (22.8\% vs $14.5 \%)$, eye pruritus ( $11.0 \%$ vs $5.5 \%)$, allergic conjunctivitis $(9.4 \%$ vs $5.2 \%)$, conjunctival folliculosis $(9.2 \%$ vs $4.9 \%)$, oral dryness (9.2\% vs $2.1 \%)$, and conjunctival allergy/inflammation (39.8\% vs $26.0 \%$ ) compared with the FCBT group (Sherwood 
et al 2006). Ocular stinging was more common with FCBT than with brimonidine alone $(\mathrm{p}=0.03)$. The timolol group had significantly less conjunctival hyperemia (7.4\%), eye pruritus $(2.8 \%)$, allergic conjunctivitis $(0.3 \%)$, conjunctival folliculosis $(1.8 \%)$, oral dryness $(0.5 \%)$, and conjunctival inflammation $(12.0 \%)$ than FCBT, and similar rates of ocular stinging (6.6\%). Similar adverse events profile has been documented in studies directly comparing brimonidine with timolol (Schuman 1996; Katz et al 1999).

When compared with concomitant brimonidine/timolol, FCBT group had higher incidence of adverse events $(30.3 \%$ vs $24.6 \%)$ or $1+$ treatment-related adverse events $(20.2 \%$ vs $14.2 \%$ ), although neither was statistically significant (Goni et al 2005). Ocular pain, pruritus, and headache were reported most often. No significant differences between groups were found for discontinuation of treatment from treatment-related adverse events, or biomicroscopic or ophthalmoscopic findings between groups (Goni et al 2005).

Reduced allergy levels with FCBT could be attributed to twice daily dosing as opposed to 3 times daily for brimonidine monotherapy, thus reducing brimonidine exposure. Alvarado postulated that the difference can be explained at a cellular level (Alvarado 2007). Adrenergic agonists reduce cell volume, increase intercellular fluid flow, and potentially allow greater access of proinflammatory mediators to the subconjunctival space. The addition of a $\beta$-blocker counteracts the cell volume effects of adrenergic agonists (Alvarado 2007). Interestingly, Osborne et al noted a significant delay in brimonidine-induced allergy among patients previously receiving timolol maleate (Osborne et al 2005). In this study, brimonidine was discontinued due to allergy on 73 per 100,000 patient treatment days, a far higher frequency than for other preparations. Patients with allergy to both brimonidine and another preparation (timolol, dorzolamide, or latanoprost) had a shorter interval between the first and second allergy if brimonidine allergy occurred first.

Reported systemic effects of FCBT in key studies were few and consistent with the individual components (Sherwood et al 2006). Small but statistically significant changes in heart rate (2-3 beats per minute) and blood pressure were found in the FCBT and timolol-treated group. Two patients from the timolol group were hospitalized due to serious treatment-related complications; one patient with respiratory distress, the other with tachycardia, nausea, and sweating (Sherwood et al 2006). No systemic adverse events were noted for brimonidine.

Well-recognized problems of topical timolol identified from other studies include cardiac failure, bradycardia
(Schuman 1996; Katz et al 1999) and heart block, bronchospasm and respiratory arrest. Confusion, headaches, reduced exercise tolerance, nocturnal hypotension, and impotence, have also been reported (Stewart and Garrison 1998). The most frequent systemic side effects reported from brimonidine were fatigue and dry mouth (Derick et al 1997). Some studies have observed statistically significant decreases in mean blood pressure without clinical symptoms with brimonidine $0.2 \%$ and $0.5 \%$ treatment (Derick et al 1997). Differences to other studies (Craven et al 2005; Goni et al 2005; Sherwood et al 2006) in systemic side effect profile may be explained by selection bias, as patients with a history of adverse events with $\beta$-blocker therapy, previous poor response to $\beta$-blockers, or systemic contraindications to the medication were excluded. Brimonidine use is not limited by pulmonary and cardiovascular contraindications. Brimonidine does not exhibit tachyphylaxis in clinical trials from 12 months (Nordlund et al 1995; Schuman 1996; Serle 1996) up to 4 years (Adkins 1998; Cantor 2000).

Compared with FCDT, FCBT has significantly less stinging and burning on application $(\mathrm{p}=0.027$ ) (Arcieri et al 2007). This finding is supported by a single-center, randomized, paired-eye study of 30 subjects without significant ocular surface disease (Chan et al 2007). FCBT was significantly more comfortable than FCDT on instillation ( $p<0.0001$ ), but not at 5 minutes. This is also in agreement with earlier studies (Sall et al 2003; Solish et al 2004) where FCDT treatment was compared with concomitant brimonidine/timolol. Over a 6-month study period, ocular stinging and burning, and dysgeusia were reported more frequently with FCDT (Sall et al 2003). The study by Arcieri et al may be too short in duration to allow for development of allergic effects and the study not powered sufficiently to detect a difference (Arcieri et al 2007).

Compared with FCLT, concomitant brimonidine/timolol had a similar adverse event profile on one (Stewart et al 2003) but not in another study (Garcia-Sanchez et al 2004). In the latter study, treatment-related adverse events were greater in the FCBT group (18.6\% vs 7.3\%). Allergy was found in $2.4 \%$ of FCLT patients compared with $7.8 \%$ of concomitant brimonidine/timolol group. Higher discontinuation rates were found with FCBT (17.3\% vs 6.0\%), with most subjects discontinuing treatment because of adverse events $(10.8 \%$ vs $1.8 \%)$.

\section{Dosage and administration}

FCBT is indicated for the reduction of IOP in patients with POAG or $\mathrm{OH}$ who are insufficiently responsive to topical 
$\beta$-blockers. The recommended dosage is 1 drop into the affected eye twice daily.

Contraindications to FCBT include hypersensitivity to the individual components, monoamine oxidase inhibitor use, bronchospasm, bronchial asthma, severe chronic obstructive pulmonary disease, sinus bradycardia, second or third degree atrioventricular block, or overt cardiac failure or cardiogenic shock (MIMS 2007).

Precautions with FCBT use include cardiac, renal or hepatic failure, depression, cerebral or coronary insufficiency, severe peripheral and central circulatory disorders, Prinzmetal angina, Raynaud's phenomenon, orthostatic hypotension, thromboangiitis obliterans, spontaneous hypoglycemia (diabetes), hyperthyroidism, myasthenia gravis, general anesthesia, history of atopy and anaphylaxsis, and use in neonates or pregnancy (MIMS 2007).

\section{Conclusion}

Clinical trials and utilization studies have demonstrated that many patients with $\mathrm{POAG}$ or $\mathrm{OH}$ require multiple medications to achieve adequate control of IOP (Fechtner and Realini 2004). Trials have established IOP additivity of concomitant brimonidine $0.2 \% 2$ or 3 times daily and timolol $0.5 \%$ twice daily. FCBT has been shown in large multi-center randomized trials to be more efficacious in lowering IOP than monotherapy with its constituent parts. It is noninferior to unfixed concomitant use of brimonidine and timolol each given twice daily. FCBT or concomitant brimonidine/timolol are as efficacious as FCDT. However, as adjuncts to timolol treatment, brimonidine is more effective in lowering IOP than dorzolamide. Compliance issues with dorzolamide include stinging on application, 3 times daily dosing, and excessive somnolence and fatigue. FCLT provides greater efficacy than concomitant timolol and brimonidine. Unfortunately no published studies have evaluated FCLT compared with FCBT.

Local and systemic adverse events for FCBT were predictable and based on that of the individual components used alone and concomitantly. No unexpected or serious adverse events associated with the fixed combination were reported in the major trials of FCBT. However, this may reflect selection bias, as patients with a history of adverse events with $\beta$-blocker therapy, previous poor response to $\beta$-blockers, or systemic contra-indications to the medication were excluded. FCBT may be advantageous over FCDT with respect to ocular tolerability and comfort, hence enhanced compliance.

In summary, FCBT is a safe and efficacious treatment for elevated IOP for patients with POAG or $\mathrm{OH}$ uncontrolled on monotherapy. Studies evaluating FCBT compared with FCLT and compared with concomitant brimonidine/latanoprost are required.

\section{Disclosures}

Neither author has any conflicts of interest to disclose.

\section{Drug name}

Combigan $^{\mathrm{TM}}$ (Allergan Inc., Irvine, CA, USA).

\section{References}

Adkins JC, Balfour JA. 1998. Brimonidine. A review of its pharmacological properties and clinical potential in the management of open-angle glaucoma and ocular hypertension. Drugs Aging, 12:225-41.

Alm A, Stjernschantz J. 1995. Effects on intraocular pressure and side effects of $0.005 \%$ latanoprost applied once daily, evening or morning. A comparison with timolol. Scandinavian Latanoprost Study Group. Ophthalmol, 102:1743-52.

Alvarado JA. 2007. Reduced ocular allergy with fixed-combination $0.2 \%$ brimonidine- $0.5 \%$ timolol. Arch Ophthalmol, 125:717-8.

Arcieri ES, Arcieri RS, Pereira AC, et al. 2007. Comparing the fixed combination brimonidine-timolol versus fixed combination dorzolamide-timolol in patients with elevated intraocular pressure. Curr Med Res Opin, 23:683-9.

Arici MK, Sayici M, Toker M, et al. 2002. A short term study of the additive effect of timolol and brimonidine on intraocular pressure. Eye, 16:39-43.

Boyle JE, Ghosh K, Gieser DK, et al. 1998. A randomised trial comparing the dorzolamide-timolol combination given twice daily to monotherapy with timolol and dorzolamide. Dorzolamide-Timolol Study Group. Ophthalmol, 105:1945-51.

Broadway DC, Grierson I, O’Brien C, et al. 1994. Adverse effects of topical anti-glaucoma medication. II. The outcome of filtration surgery. Arch Ophthalmol, 112:1446-54.

Burke JA, Potter DE. 1986. The ocular effects of relatively selective $\alpha$-agonist (UK 14,304-18) in cats, rabbits and monkeys. Curr Eye Res, 5:665-76.

Burke J, Schwartz M. 1996. Preclinical evaluation of brimonidine. Surv Ophthalmol, 41(suppl 1):S9-18.

Camras CB. 1996. Comparison of latanoprost and timolol in patients with ocular hypertension and glaucoma: a 6 month masked, multicenter trial in the United States. The United States Latanoprost Study Group. Ophthalmol, 103:138-47.

Cantor LB. 2000. The evolving pharmacotherapeutic profile of brimonidine, an alpha 2-adrenergic agonist, after four years of continuous use. Expert Opin Pharmacother, 1:815-34.

Centofanti M, Manni GL, Gregori D, et al. 1999. Brimonidine $0.2 \%$ behaviour on intraocular pressure in timolol-uncontrolled glaucomatous patients. Acta Ophthalmol Scand Suppl, 77:52.

Centofanti M, Manni G, Gregori D, et al. 2000. Comparative acute effects of brimonidine $0.2 \%$ versus dorzolamide $2 \%$ combined with beta-blockers in glaucoma. Graefes Arch Clin Exp Ophthalmol, 238:302-5.

Chan K, Testa M, McCluskey P. 2007. Ocular comfort of combination glaucoma therapies:brimonidine $0.2 \%$ /timolol $0.5 \%$ compared with dorzolamide 2\%/timolol 0.5\%. J Ocul Pharmacol Ther, 23:372-6.

Chrai SS, Makoid MC, Eriksen SP, et al. 1974. Drop size and initial dosing frequency problems of topically applied ophthalmic drugs. J Pharm Sci, 63:333-8.

Clineschmidt CM, Williams RD, Snyder E, et al. 1998. A randomised trial in patients inadequately controlled with timolol alone comparing the dorzolamide-timolol combination to monotherapy with timolol or dorzolamide. Dorzolamide-Timolol Combination Study Group. Ophthalmol, 105:1952-9. 
Craven ER, Walters TR, Williams R, et al. Combigan Study Group. 2005. Brimonidine and timolol fixed-combination therapy versus monotherapy: a 3-month randomized trial in patients with glaucoma or ocular hypertension. J Ocul Pharmacol Ther, 21:337-48.

David R, Walters TR, Sargent JB, et al. 1995. The safety and efficacy of brimonidine tartrate $0.08 \%, 0.2 \%, 0.35 \%$, and $0.5 \%$ in normotensive subjects. Eur J Ophthalmol, 5(suppl 2A):156.

Derick RJ, Robin AL, Walters TR, et al. 1997. Brimonidine tartrate: a one month dose response study. Ophthalmol, 104:131-6.

Fechtner RD, Realini T. 2004. Fixed combinations of topical glaucoma medications. Curr Opin Ophthalmol, 15:132-5.

Frampton JE. 2006. Topical brimonidine $0.2 \% /$ timolol $0.5 \%$ ophthalmic solution: in glaucoma and ocular hypertension. Drugs Aging, 23:753-61.

García-Sánchez J, Rouland JF, Spiegel D, et al. 2004. A comparison of the fixed combination of latanoprost and timolol with the unfixed combination of brimonidine and timolol in patients with elevated intraocular pressure. A six month, evaluator masked, multicentre study in Europe. Br J Ophthalmol, 88:877-83.

Goñi FJ; Brimonidine/Timolol Fixed Combination Study Group. 2005. 12 -week study comparing the fixed combination of brimonidine and timolol with concomitant use of the individual components in patients with glaucoma and ocular hypertension. Eur J Ophthalmol, 15:581-90.

Heijl A, Leske C, Bengtsson B, et al. 2002. Early Manifest Glaucoma Trial Group. Reduction of intraocular pressure and glaucoma progression: results from the Early Manifest Glaucoma Trial. Arch Ophthalmol, $120: 1268-79$

Javitt JC, Schiffman RM; the Brimonidine Outcomes Study Group 1. 2000. Clinical success and quality of life with brimonidine $0.2 \%$ or timolol $0.5 \%$ used twice daily in glaucoma and ocular hypertension:a randomised clinical trial. J Glauc, 9:224-34.

Kass MA, Heuer DK, Higginbotham EJ, et al. 2002. The Ocular Hypertension Treatment Study: a randomised trial determines that topical ocular hypotensive medication delays or prevents the onset of primary openangle glaucoma. Arch Ophthalmol, 120:701-13.

Katz LJ; the Brimonidine Study Group. 1999. Brimonidine tartrate $0.2 \%$ twice daily vs timolol $0.5 \%$ twice daily: 1-year results in glaucoma patients. Am J Ophthalmol, 127:20-6.

Kiland JA, Gabelt BT, Kaufman PL. 2004. Studies on the mechanism of action of timolol and on the effects of suppression and redirection of aqueous flow on outflow facility. Exp Eye Res, 78:639-51.

Kobelt-Nguyen G, Gerdtham UG, Alm A. 1998. Costs of treating primay open angle glaucoma and ocular hypertension:a retrospective, observational two-year chart review of newly diagnosed patients in Sweden and the United States. J Glaucoma, 7:95-104.

Konstas AG, Katsimpris IE, Kaltsos K, et al. 2007. Twenty-four-hour efficacy of the brimonidine/timolol fixed combination versus therapy with the unfixed components. Eye, Jun 15 [Epub ahead of print].

Larsson L. 2001. Aqueous humor flow in normal human eyes treated with brimonidine and timolol, alone and in combination. Arch Ophthalmol, 119:492-5.

Le Blanc RP; the Brimonidine Study Group 2. 1998. Twelve-month results of an ongoing randomised trial comparing brimonidine tartrate $0.2 \%$ and timolol $0.5 \%$ given twice daily in patients with glaucoma or ocular hypertension. Ophthalmol, 105:1960-67.

Lee DA, Gornbein JA. 2001. Effectiveness and safety of brimonidine as adjuntive therapy for patients with elevated intraocular pressure in a large open-label community trial. J Glauc, 10:220-6.

Lichter PR, Musch DC, Gillespie BW, et al. 2001. CIGTS Study Group. Interim clinical outcomes in the Collaborative Initial Glaucoma Treatment Study comparing initial treatment randomised to medications or surgery. Ophthalmol, 108:1943-53.

Melamed S, David R, the Brimonidine Study Group 2. 2000. Ongoing clinical assessment of the safety profile and efficacy of brimonidine compared with timolol:year-three results. Clin Ther, 22:103-11.

MIMS, Ophthalmology Prescribing Guide, January 2007. p 26-9.
Mishima HK, Masuda K, Kitazawa Y, et al. 1996. A comparison of latanoprost and timolol in primary open-angle glaucoma and ocular hypertension. Arch Ophthalmol, 114:929-32.

Nordlund JR, Pasquale LR, Robin AL, et al. 1995. The cardiovascular, pulmonary and ocular hypotensive effects of $0.2 \%$ brimonidine. Arch Ophthalmol, 113:77-83.

Osborne SA, Montgomery DM, Morris D, et al. 2005. Alphagan allergy may increase the propensity for multiple drop allergy. Eye, 19:129-37.

Quigley HA. 1996. Number of people with glaucoma worldwide. Br J Ophthalmol, 80:389-93.

Sall KN, Greff LJ, Johnson-Pratt LR, et al. 2003. Dorzolamide/timolol combination versus concomitant administration of brimonidine and timolol: six-month comparison of efficacy and tolerability. Ophthalmol, 110:615-24

Schuman JS. 1996. Clinical experience with brimondine $0.2 \%$ and timolol $0.5 \%$ in glaucoma and ocular hypertension. Surv Ophthalmol, 41(Suppl 1):S27-37.

Schuman JS, Horwitz B, Choplin NT, et al; the Chronic Brimonidine Study Group. 1997. A 1-year study of brimonidine twice daily in glaucoma and ocular hypertension. Arch Ophthalmol, 115:847-52.

Schwartz K, Budenz D. 2004. Current management of glaucoma. Curr Opin Ophthalmol, 15:119-26.

Serle JB. 1996. A comparison of the safety and efficacy of twice daily brimonidine $0.2 \%$ versus betaxolol $0.25 \%$ in subjects with elevated intraocular pressure. The Brimonidine Study Group III. Surv Ophthalmol, 41(Suppl 1):S39-47.

Serle JB, Podos SM, Lee P-Y, et al. 1991. Effect of $\alpha 2$-adrenergic agonists on uveoscleral outflow in rabbits. Invest Ophthalmol Vis Sci, 32(Suppl):867.

Sherwood MB, Craven ER, Chou C, et al. 2006. Twice-daily $0.2 \%$ brimonidine- $0.5 \%$ timolol fixed-combination therapy vs monotherapy with timolol or brimonidine in patients with glaucoma or ocular hypertension: a 12-month randomized trial. Arch Ophthalmol, 124:1230-8.

Simmons ST; Alphagan/Trusopt Study Group. 2001. Efficacy of brimonidine $0.2 \%$ and dorzolamide $2 \%$ as adjunctive therapy to beta-blockers in adult patients with glaucoma or ocular hypertension. Clin Ther, 23:604-19.

Solish AM, DeLucca PT, Cassel DA, et al. 2004. Dorzolamide/timolol fixed combination versus concomitant administration of brimonidine and timolol in patients with elevated intraocular pressure: a 3-month comparison of efficacy, tolerability, and patient-reported measures. J Glauc, 13:149-57.

Stewart WC, Day DG, Stewart JA, et al. 2000a. Therapeutic success of latanoprost $0.005 \%$ compared to brimonidine $0.2 \%$ in patients with open-angle glaucoma or ocular hypertension. J Ocul Pharmacol Ther, 16:557-64.

Stewart WC, Day DG, Stewart JA, et al. 2001. The efficacy and safety of latanoprost $0.005 \%$ once daily versus brimonidine $0.2 \%$ twice daily in openangle glaucoma or ocular hypertension. Am J Ophthalmol, 131:631-5.

Stewart WC, Garrison PM. 1998. Beta-blocker-induced complications and the patient with glaucoma. Newer treatments to help reduce systemic adverse events. Arch Intern Med, 158:221-6.

Stewart WC, Sharpe ED, Day DG, et al. 2000b. Comparison of the efficacy and safety of latanoprost $0.005 \%$ compared to brimonidine $0.2 \%$ or dorzolamide $2 \%$ when added to a topical beta-adrenergic blocker in patients with primary open angle glaucoma or ocular hypertension. J Ocul Pharmacol Ther, 16:251-9.

Stewart WC, Stewart JA, Day D, et al. 2003. Efficacy and safety of timolol maleate/latanoprost fixed combination versus timolol maleate and brimonidine given twice daily. Acta Ophthalmol Scand, 81:242-6.

Stjernschantz J, Resul B. 1992. Phenyl substituted prostaglandin analogues for glaucoma treatment. Drugs Future, 17:691-704.

Strohmaier K, Snyder E, DuBiner H, et al. 1998. The efficacy and safety of the dorzolamide-timolol combination versus the concomitant administration of its components. Dorzolamide-Timolol Study Group. Ophthalmol, 105:1936-44.

The Advanced Glaucoma Intervention Study (AGIS) 7. 2000. The relationship between control of intraocular pressure and visual field deterioration. The AGIS investigators. Am J Ophthalmol, 130:429-40. 
Thylefors B, Negrel AD. 1994. The global impact of glaucoma. Bull World Health Organ, 72:323-6.

Toris CB, Camras CB, Yablonski ME. 1993. Effects of PhXA41, a new prostaglandin $\mathrm{F} 2 \alpha$ analog, on aqueous humor dynamics in human eyes. Ophthalmol, 100:1297-304.

Toris CB, Gleason ML, Camras CB, et al. 1995. Effects of brimonidine on aqueous humor dynamics in human eyes. Arch Ophthalmol, 1995; 113:1514-7.

Tsai J-C, Chang H-W. 2005. Comparison of the effects of brimonidine $0.2 \%$ and timolol $0.5 \%$ on retinal nerve fiber layer thickness on ocular hypertensive patients:a prospective, unmasked study. J Oc Pharm Ther, 21:475-82.

van der Valk R, Webers CA, Schouten JS, et al. 2005. Intraocular pressurelowering effects of all commonly used glaucoma drugs: a meta-analysis of randomized clinical trials. Ophthalmol, 112:1177-85.

Villegas-Perez M, Lafuente M, Mayor-Torroglosa S, et al. 2000. Short and long term neuroprotection of a selective alpha-2 agonist (AGN 191103) on retinal ganglion cell survival after ischaemia induced by selective ligature of the ophthalmic vessels. Invest Ophthalmol Vis Sci, 41:4169-74.
Wen R, Cheng T, Li Y, et al. 1996. Alpha2-adrenergic agonists induce basic fibroblast growth factor expression in photoreceptors in vivo and ameliorate light change. $J$ Neurosci, 16:5986-92.

WoldeMussie E, Ruiz G, Wijono M, et al. 2001. Neuroprotection of retinal ganglion cells by brimonidine in rats with laser-induced chronic ocular hypertension. Invest Ophthalmol Vis Sci, 42:2849-55.

Yoles E, Wheeler LA, Schwartz M. 1999. $\alpha 2$-Adrenoreceptor agonists are neuroprotective in a rat model of optic nerve degeneration. Invest Ophthalmol Vis Sci, 40:65-73.

Yüksel N, Altinta O, Karaba L, et al. 1999. The short-term effect of adding brimonidine $0.2 \%$ to timolol treatment in patients with openangle glaucoma. Ophthalmologica, 213:228-33.

Ziai N, Dolan JW, Kacere RD, et al. 1993. The effects on aqueous dynamics of PhXA41, a new prostaglandin F2 $\alpha$ analog, after topical application in normal and ocular hypertensive human eyes. Arch Ophthalmol, 111:1351-8. 
